\title{
Iatrogenic left ventricular-right atrial fistula following mitral valve replacement
}

\author{
RICARDO SEABRA-GOMES, DONALD N. ROSS, and \\ LORENZO GONZALEZ - LAVIN ${ }^{1}$ \\ Department of Surgery, Institute of Cardiology, and National Heart Hospital, London
}

\begin{abstract}
A case of an acquired left ventricular-right atrial fistula complicating Starr-Edwards replacement of a non-calcific mitral valve is reported. Emphasis is placed on the diagnostic methods and the anatomical relationship of the mitral valve to the atrioventricular septum. Surgical repair is advocated as soon as this complication of mitral valve replacement is discovered.
\end{abstract}

Congenital communications between the left ventricle and right atrium, first described in 1857 (Buhl, quoted by Meyer, 1857 ; Hillier, 1859), are a well-known occurrence. They can be individualized as a syndrome (Gerbode, Hultgren, Melrose, and Osborn, 1958; Braunwald and Morrow, 1960 ; Laurichesse et al., 1964 ; Riemenschneider and Moss, 1967) and successfully repaired (Kirby, Johnson, and Zinsser, 1957 ; Barclay et al., 1967; Taguchi, Matsuura, Yoshizaki, and Tamura, 1968 ; Deverall, Taylor, Aberdeen, and Waterston, 1969). Acquired left ventricular-right atrial (LV-RA) fistulas have been reported with increasing frequency and due to a multitude of aetiological factors : bacterial endocarditis (Aberg, Johansson, Michaelson, and Rhedin, 1971), chest trauma (Dunseth and Ferguson, 1965), and, more recently, after replacement of a heavily calcified mitral valve (Marsten and Hildner, 1969).

Our communication describes an acquired LVRA fistula complicating Starr-Edwards replacement of a non-calcified mitral valve in which a previous annuloplasty failed. The diagnostic methods and surgical repair of the fistula are emphasized.

\section{CASE REPORT}

C.G. (NHH 18603) is a 44-year-old woman with no definite history of rheumatic fever in whom, at the age of 20 years, a heart murmur was noted on a routine physical examination. She remained asymptomatic until 32 years of age. Two years later, in 1962, she was admitted to hospital because of progressive breathlessness and the diagnosis of mitral

1Correspondence to: Lorenzo Gonzalez-Lavin, M.D., Division of Thoracic Surgery, Henry Ford Hospital, 2799 "West Grand Boulevard, Detroit, Michigan 48202, U.S.A. stenosis was made. The patient underwent a closed mitral valvotomy at another hospital with good symptomatic relief until 1970 when she developed increasing breathlessness, orthopnoea, and paroxysmal nocturnal dyspnoea. On admission to the National Heart Hospital (8 November 1970) she was in congestive heart failure due to severe mitral regurgitation. Cardiac catheterization confirmed the clinical diagnosis (Table). At operation (27 November 1970) the mitral valve was found to be grossly regurgitant with a dilated annulus and ruptured chordae tendineae along the anterior leaflet. An annuloplasty was performed on the posterior commissure with interrupted sutures incorporating Teflon pledgets. The valve, tested by filling the left ventricle under pressure, had a small leak near the centre of the mitral

T A B L E

CARDIAC CATHETERIZATIONS

\begin{tabular}{|c|c|c|c|}
\hline & 16 Nov. '70 & 15 Nov. '71 & 14 Feb. '72 \\
\hline $\begin{array}{l}\text { RA } \\
\text { Pressure } \\
\text { Saturation } \\
\text { RV }\end{array}$ & $\begin{array}{l}(9) \\
50 \%\end{array}$ & (5) & $\begin{array}{l}(22) \\
60 \%\end{array}$ \\
\hline $\begin{array}{l}\text { Pressure } \\
\text { Saturation } \\
\text { PA }\end{array}$ & $\begin{array}{c}110 / 10 \\
49 \%\end{array}$ & $80 / 5$ & $\begin{array}{l}80 / 20 \\
60 \%\end{array}$ \\
\hline & $\begin{array}{c}110 / 50 \\
(72)\end{array}$ & $\begin{array}{c}85 / 40 \\
(60)\end{array}$ & $\begin{array}{c}80 / 45 \\
(60)\end{array}$ \\
\hline $\begin{array}{l}\text { Saturation } \\
\text { Wedge pressure }\end{array}$ & $\begin{array}{c}52 \% \\
(26) \\
V=35\end{array}$ & $\mathrm{~V}=38$ & $\begin{array}{c}62 \% \\
(18) \\
V=22\end{array}$ \\
\hline $\begin{array}{l}\text { LV } \\
\text { Pressure } \\
\text { Saturation } \\
\text { Aorta } \\
\text { pressure }\end{array}$ & $\begin{array}{c}150 / 17 \\
76 \% \\
155 / 112\end{array}$ & $\begin{array}{c}105 / 5-10 \\
100 / 80\end{array}$ & $\begin{array}{c}105 / 15-17 \\
81 \% \\
105 / 75\end{array}$ \\
\hline $\begin{array}{l}\text { Degree of mitral } \\
\text { regurgitation } \\
\text { Indirect gradient } \\
\text { mitral valve }\end{array}$ & $\begin{array}{c}3 / 4 \\
12 \mathrm{mmHg}\end{array}$ & $\begin{array}{c}3 / 4 \\
12 \mathrm{mmHg}\end{array}$ & $\begin{array}{l}\text { None } \\
\text { None }\end{array}$ \\
\hline
\end{tabular}

Cardiac catheterizations performed before mitral annuloplasty, mitral Starr replacement, and repair of the LV-RA fistula. Notice the highest right atrial pressure with increased $\mathrm{O}_{2}$ saturation and persistent high pulmonary artery and wedge pressures after mitral Starr valve replacement. 
orifice. The mean left atrial pressure was $18 \mathrm{mmHg}$, the left ventricular end-diastolic pressure 15 , and the right ventricular pressure $40 / 6$.

A soft systolic apical murmur, grade $2 / 6$, was heard immediately after surgery. The patient improved symptomatically for nine months after which she deteriorated and presented with severe shortness of breath and tiredness. After assessment she was found to have severe mitral regurgitation necessitating further surgery.

At operation (14 January 1972) it was found that the previous annuloplasty sutures had pulled through the surrounding area was fibrosed, and the pledgets were embedded deep in the annular tissue. A wider dissection than usual was necessary to excise the mitral valve and, in the process, dark venous blood was seen spurting from the region of the posterior commissure. Several interrupted mattress sutures were placed in that area which appeared to obliterate the communication. A 2M (model 6120) Starr-Edwards prosthesis was inserted with multiple interrupted sutures. At the end of the procedure, the mean right atrial pressure was $6 \mathrm{mmHg}$, the mean left atrial pressure 12 with a ' $V$ ' wave of 20 , and the arterial pressure $90 / 50$.
The postoperative course was complicated by dysrhythmic episodes (prolonged P-R interval, wandering pacemaker, and nodal rhythm with frequent ven- 흘 tricular ectopics) requiring demand atrial pacing. $\frac{\bar{s}}{\bar{D}}$ Signs and symptoms of congestive heart failure per- $\mathbb{D}$ sisted despite intensive antifailure treatment.

Clinical examination revealed a hyperdynamic left के and right precordium and a systolic murmur grade $\overrightarrow{0}$ $3 / 6$, best audible at the left sternal edge-aortic area, not radiating to the axilla.

The chest radiograph revealed increased heart size and pulmonary venous congestion (Fig. 1). The elec- $\vec{x}$ trocardiogram, in sinus rhythm, showed no im- i portant differences from previous tracings (Fig. 2). A phonocardiogram confirmed a systolic murmur and $N$ short aortic second sound. The mitral prosthesis opening interval $(50 \mathrm{msec})$ suggested high left atrial $\mathrm{G}$ pressure (Fig. 3). The prosthesis functioned normally on $\frac{}{2}$ echocardiogram (Fig. 4). A left ventricular-right atrial $\overrightarrow{ }$ communication was evident from cardiac catheterization and a left ventricular angiogram (Fig. 5).

Re-operation was carried out on 20 February 1972 . $\stackrel{\rho}{\supset}$ The right atrium was dilated and the right ventricle $\vec{\theta}$ prominent. A thrill was palpable over the right $\frac{0}{\omega}$

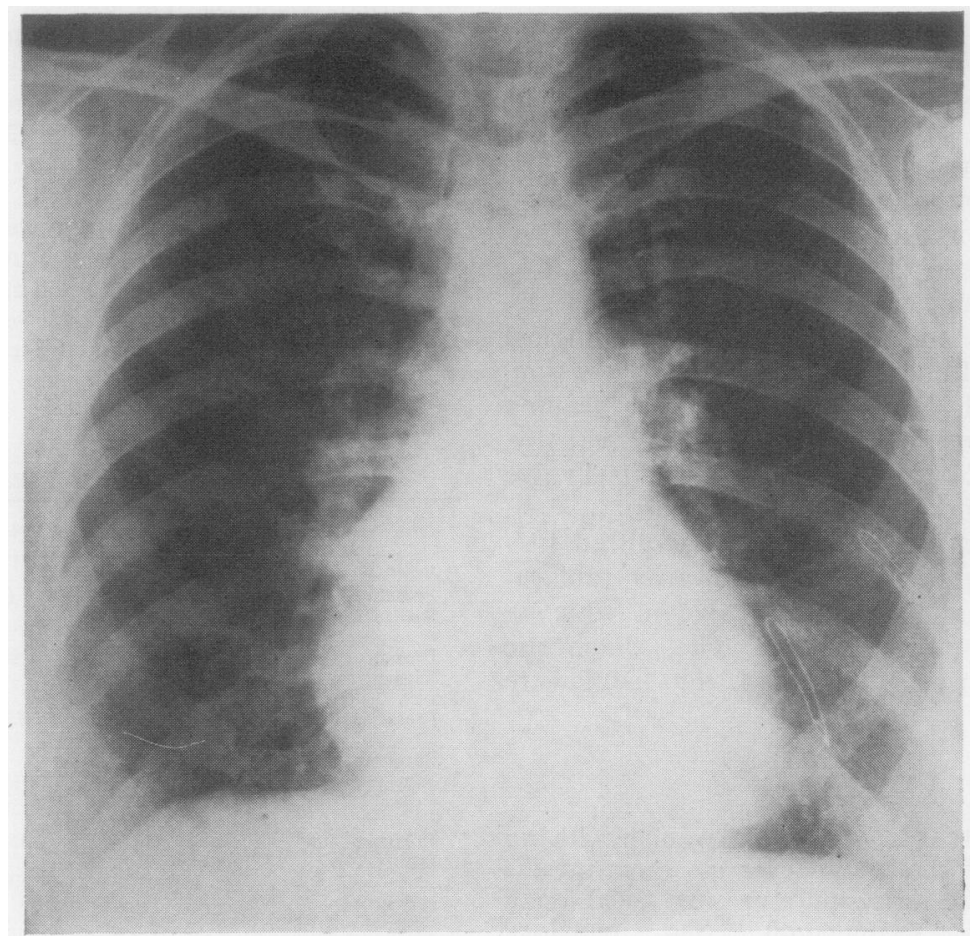

IG. 1 a.

FIG. 1. (a) (15 November 1971). Plain chest film showing increase in heart size; (b) (24 February 1972) more prominent pulmonary vascularity after Starr valve replacement; (c) (27 March 1972) improvement after repair of the fistula. $A$ left pleural effusion was also present in $(c)$. 


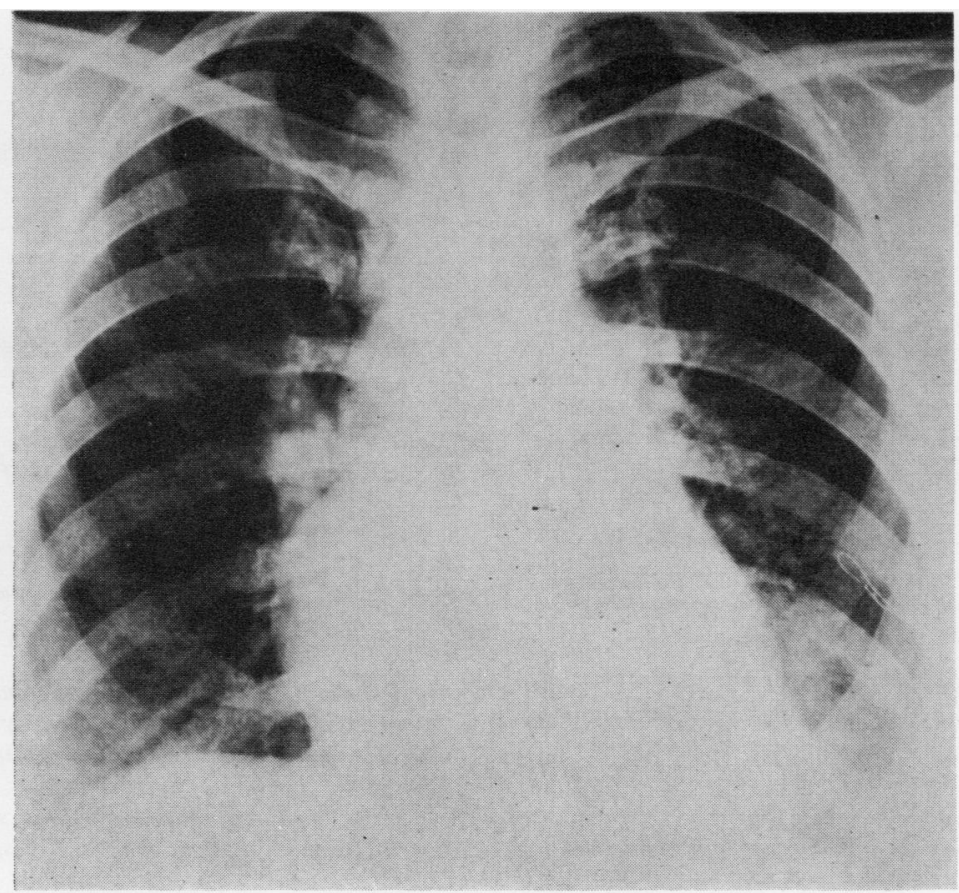

FIG. $1 \mathrm{~b}$.

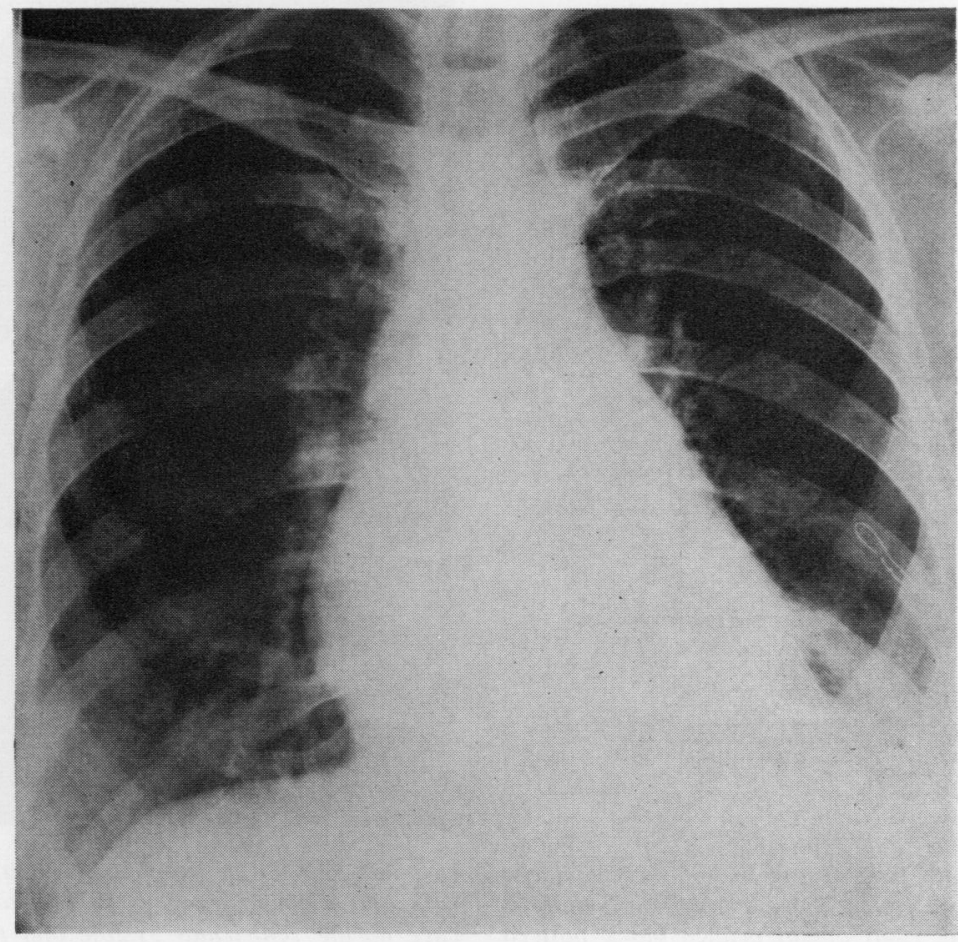

FIG. 1c. 


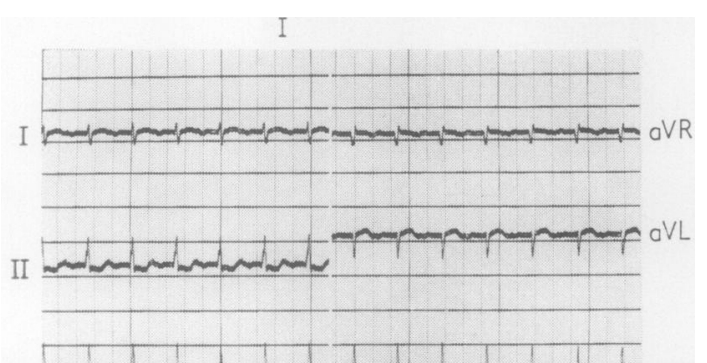

III

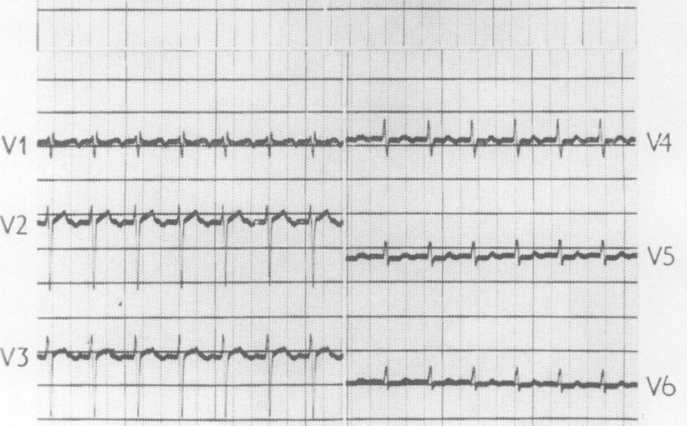

II

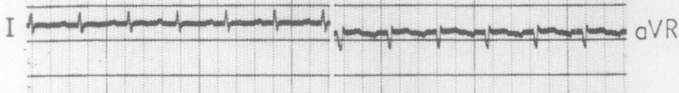

II

III

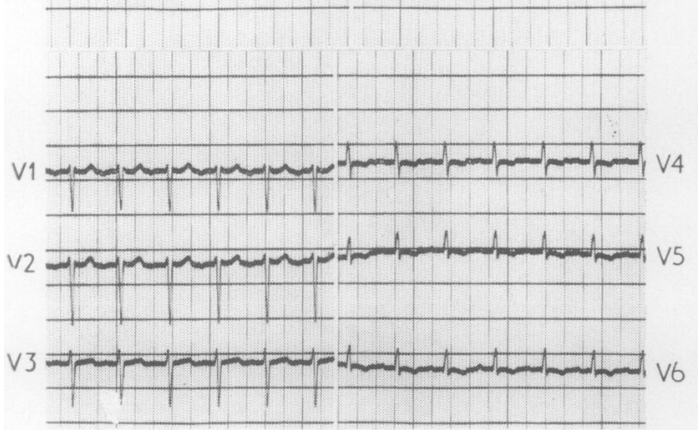

FIG. 2. Electrocardiograms before (I, $21 \mathrm{Feb}$. '72) and after (II, 4 Apr. '72) repair of the fistula showing basic sinus rhythm with prolonged $P-R$ interval and digitalis effect. The incomplete right bundle-branch block noticed after mitral Starr replacement is almost reverted.

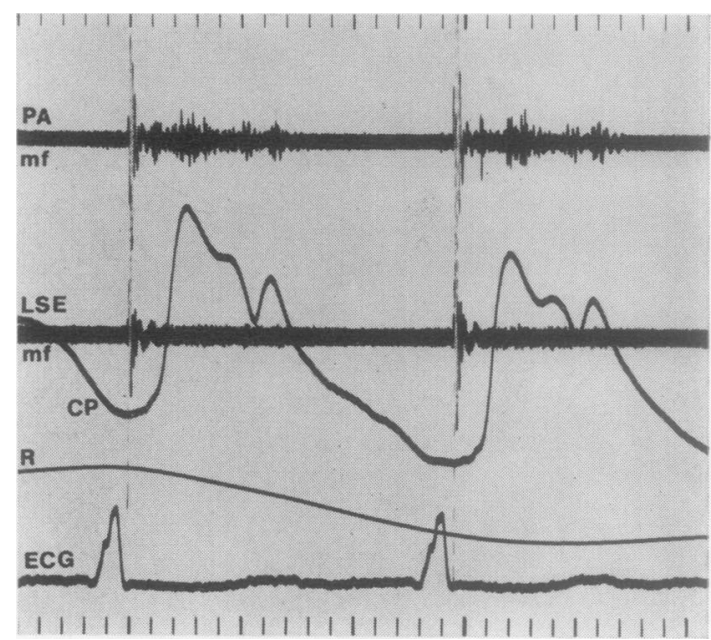

FIG. 3. Phonocardiogram in pulmonary area $(P A)$ and $\stackrel{\rho}{\triangle}$ left sternal edge (LSE), simultaneously with ECG (lead-II), $\overrightarrow{0}$ indirect carotid pulse $(C P)$ and respiratory $(R)$ tracings. $\omega$ They show the holosystolic murmur, better recorded in $P A$, reduced mitral Starr opening sound with a short interval from $A_{2}$ not moving with respiration.

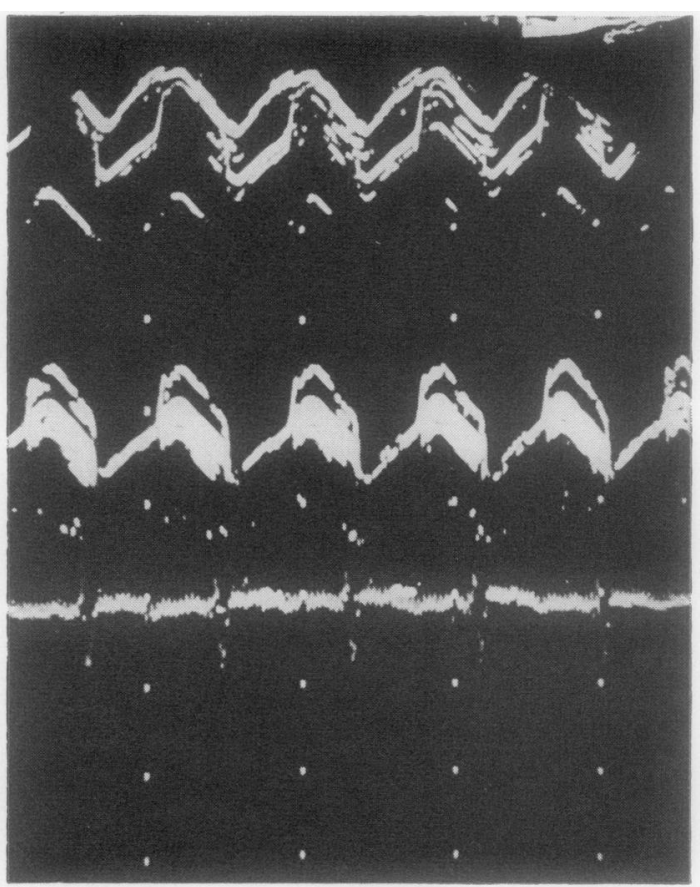

FIG. 4. Echocardiogram of the mitral Starr prosthesis with normal apposition of the ball to the annulus of the cage during ventricular systole and to the vertex during diastole. 


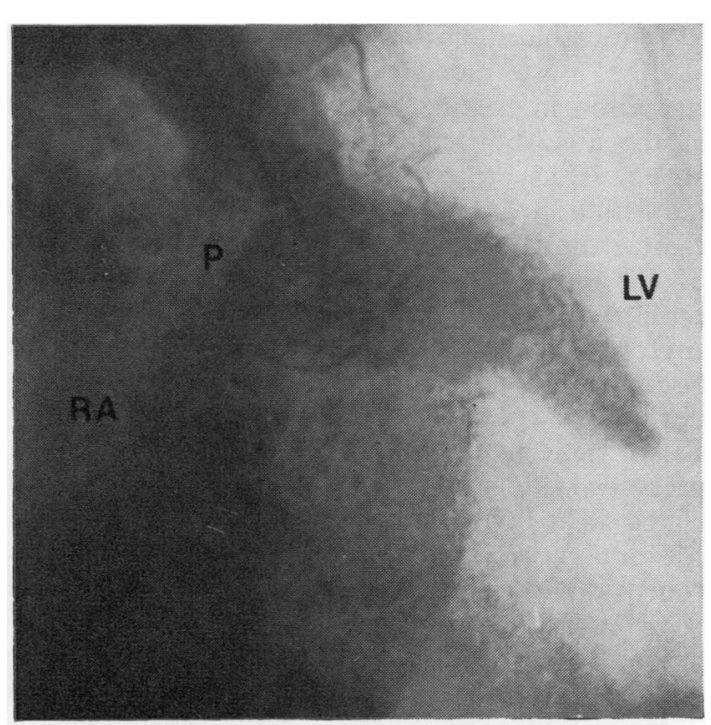

(a)

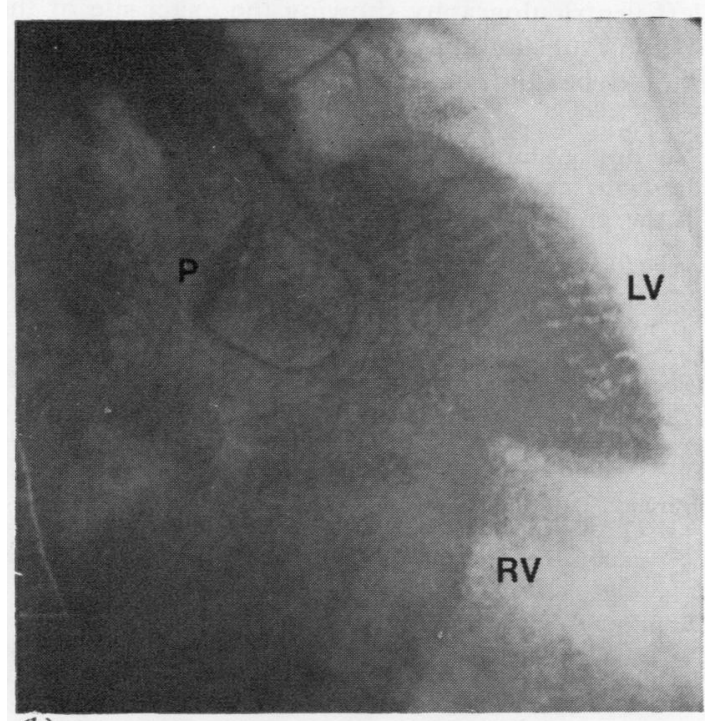

(b)

FIG. 5. Left ventricular cineangiograms in the right anterior oblique view showing (a) the contrast entering the right atrium $(R A)$ directly from the left ventricle $(L V)$ and later (b) filling the right ventricle $(R V)$. No mitral regurgitation is seen through the mitral Starr prosthesis.

atrium and digital examination of the right atrial cavity confirmed the presence of a systolic rush of blood through the atrial septum. Cardiopulmonary by-pass was instituted and the left atrium was opened first. The valve prosthesis was well incorporated into the mitral annulus by pseudothelium which covered most of the sewing ring. No dehiscence or perivalvular leaks were present. The right atrium was opened. A $1 \mathrm{~cm}$ fenestrated laceration of the atrial septum was present a few millimetres above the coronary sinus. The sewing ring of the mitral prosthesis could be seen through the fistula (Fig. 6). The communication was

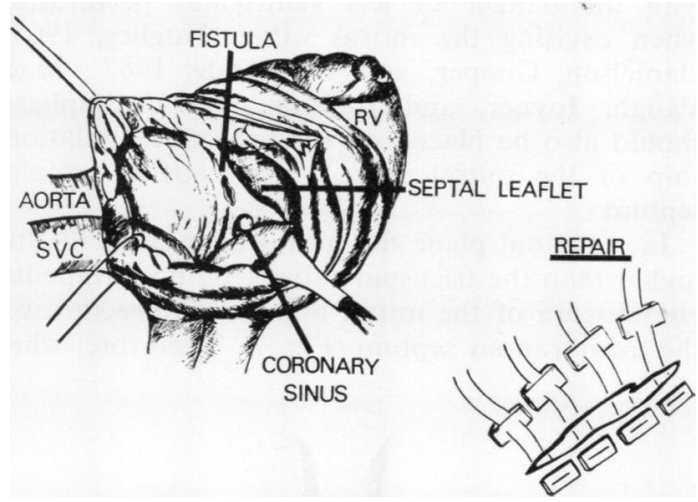

FIG. 6. Diagrammatic section of right atrium showing relationship of the fistula to the coronary sinus and the septal leaflet of the tricuspid valve.

closed with interrupted stitches reinforced with Teflon pledgets. The heart came off bypass in $A-V$ dissociation and epicardial leads were attached to the right ventricle. By the end of the procedure, however, sinus rhythm had resumed, the mean right atrial pressure was $4 \mathrm{mmHg}$ with a ' $\mathrm{V}$ ' wave of 6 , and the mean left atrial pressure was 4 with a ' $V$ ' wave of $9 \mathrm{mmHg}$. Demand pacing was necessary in the postoperative period to control supraventricular arrhythmias. The patient progressed to a stable haemodynamic state and was discharged on 4 April 1972. When last seen two months later, she was asymptomatic. The jugular venous pressure was normal. On auscultation she had a regular rhythm and sounds of a normally functioning mitral valve prosthesis.

\section{DISCUSSION}

Replacement of severely diseased heart valves with biological or prosthetic substitutes is the best method of treatment. With increasing experience the operative mortality has steadily decreased; however, an increase in the variety of operative complications has been reported. Iatrogenic complications alter mitral valve replacement vary from perforation of the left ventricular wall, circumflex coronary occlusion by suture, and subannular aneurysm, to acquired LV-RA communication. Knowledge of their likelihood should decrease their incidence. It becomes impor- 
tant then to review relevant points in cardiac anatomy.

Recently the proximity of the circumflex coronary artery to the posterior aspect of the mitral annulus has been emphasized, as has the extension of calcification of the posterior leaflet of the mitral valve down to the ventricular wall with the danger of left ventricular perforation when excising the mitral valve (Hughes, 1965; Danielson, Cooper, and Tweeddale, 1967 ; MacVaugh, Joyner, and Johnson, 1971). Emphasis should also be placed on the anatomical relationship of the mitral valve to the atrioventricular septum.

In a sagittal plane the mitral annulus is slightly higher than the tricuspid valve. The posteromedial commissure of the mitral annulus is directly over the membranous septum (Fig. 7). Therefore, when

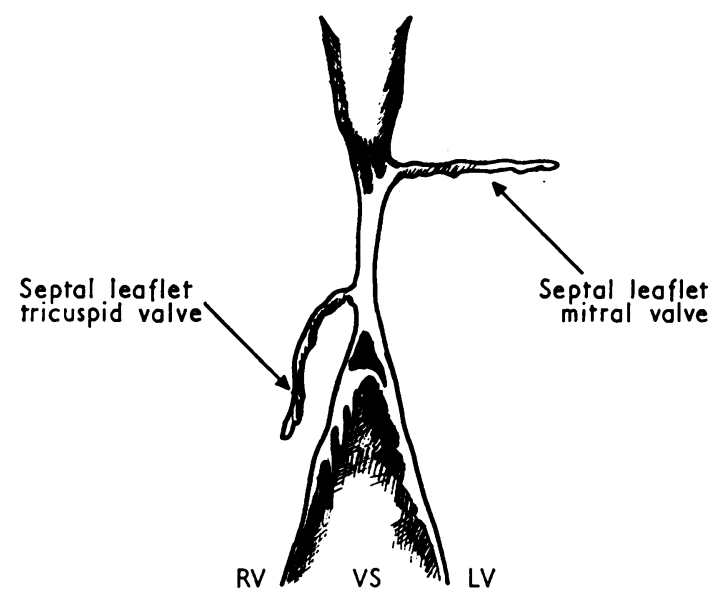

FIG. 7. Anatomical relationship between right atrium and left ventricle through the central fibrous body of the heart above the root of the septal leaflet of the tricuspid valve and the membranous portion of the ventricular septum (VS).

excision of a heavily calcified mitral valve or extensive debridement of fibrous tissue at the posteromedial commissure from previous procedures is necessary, a laceration in this area enters the right atrium above the insertion of the septal leaflet of the tricuspid valve and near the coronary sinus. The smallest laceration subjected to the persistent systolic thrust of the left ventricle may become a frank perforation. Anatomically the fistula corresponds to the first of two types of congenital LV-RA communications described by Edwards (1953).
Venous bleeding during dissection in the region of the posteromedial commissure suggests a laceration in the membranous septum. Inspection of the atrioventricular septum through the right atrium is advocated as it will most likely expose the fistula. Secure closure is obtained through the right atrium at the same operation after insertion of the mitral valve substitute, thus avoiding a prolonged and complicated postoperative course

However, the LV-RA communication may not be immediately obvious and only becomes evident during the patient's postoperative course. Persistent right heart failure and increased right atrial pressure with systolic venous pulsation are associated with this complication. A right parasternal lift and a systolic murmur at the level of the fourth or fifth intercostal spaces at the left sternal edge with radiation to the right, and not to the axilla, are helpful clinical findings. Only cardiac catheterization showing increased right atrial pressures and differential oxygen saturations indicating a left-to-right shunt at the atrial level and selective left ventriculography showing the exact site of the fistula substantiate the diagnosis. Re-operation should be undertaken without delay.

We are grateful to Miss Roberta Young for the drawings and to Miss Vicki Adler for her assistance in the preparation of the manuscript.

\section{REFERENCES}

Aberg, T., Johansson, L., Michaelsson, M., and Rhedin, B. (1971). Left ventricular-right atrial shunt of septic origin. Presentation of a case with surgical closure. J. thorac. cardiovasc. Surg., 61, 212.

Barclay, R. S., Reid, J. M., Coleman, E. N., Stevenson, J. G., Welsh, T. M., and MacSwan, N. (1967). Communication between the left ventricle and right atrium. Thorax, 22, 473.

Braunwald, E., and Morrow, A. G. (1960). Left ventriculoright atrial communication: diagnosis by clinical, hemodynamic and angiographic methods. Amer. $J$. Med., 28, 913.

Buhl, quoted by Meyer, H. (1857). Ueber angeborene Enge oder Verschluss der Lungenarterienbahn. Virchows Arch. path. Anat., 12, 497.

Danielson, G. K., Cooper, E. and Tweeddale, D. N. (1967). Circumflex coronary artery injury during mitral valve replacement. Ann. thorac. Surg., 4, 53.

Deverall, P. B., Taylor, J. F. N., Aberdeen, E., and Waterston, D. J. (1969). Left ventricular-right atrial communication. Ann. thorac. Surg., 8, 498.

Dunseth, W., and Ferguson, T. B. (1965). Acquired cardiac septal defect due to thoracic trauma. J. Trauma, 5, 142.

Edwards, J. E. (1953). Congenital malformations of the heart and great vessels. In Pathology of the Heart, edited by S. E. Gould, p. 266. Thomas, Springfield, Illinois. 
Gerbode, F., Hultgren, H., Melrose, D., and Osborn, J. (1958). Syndrome of left ventricular-right atrial shunt. Ann. Surg., 148, 433.

Hillier, T. (1859). Congenital malformation of the heart: perforation of the septum ventriculorum, establishing a communication between the left ventricle and the right auricle. Trans, path. Soc. Lond., 10, 110.

Hughes, R. K. (1965). Complications of Starr-Edwards mitral valve replacement. J. thorac. cardiovasc. Surg., 49, 731 .

Kirby, C. K., Johnson, J., and Zinsser, H. F. (1957). Successful closure of a left ventricular-right atrial shunt. Ann. Surg., 145, 392.

Laurichesse, J., Ferrane, J., Renais, J., Scebat, L., and Lenegre, J. (1964). Communication entre le ventricule gauche et l'oreillette droite. Arch. Mal. Coeur, 57, 703.
MacVaugh, H. III, Joyner, C. R., and Johnson, J. (1971). Usual complications during mitral valve replacement in the presence of calcification of the annulus. Ann. thorac. Surg., 11, 336.

Marsten, J. L., and Hildner, F. J. (1969). Left ventricularright atrial communication following valve replacement. J. thorac. cardiovasc. Surg., 58, 588.

Riemenschneider, T. A., and Moss, A. J. (1967). Left ventricular-right atrial communication. Amer. J. Cardiol., 19, 710.

Taguchi, K., Matsuura, Y., Yoshizaki, E., and Tamura, M. (1968). Surgery of atrioventricular septal defects with left ventricular-right atrial shunt. $J$. thorac. cardiovasc. Surg., 56, 265. 